\title{
Click evoked myogenic potentials in the differential diagnosis of acute vertigo
}

\author{
G Heide, S Freitag, I Wollenberg, H Iro, K Schimrigk, U Dillmann
}

\begin{abstract}
Objective-In response to loud clicks, a vestibular evoked potential can be recorded from sternocleidomastoid muscles, called "click evoked myogenic potential" (CEMP). This paper reports on the usefulness of CEMP in the differential diagnosis of acute vertigo of presumed vestibular origin.

Methods-CEMP was examined in 40 patients with acute vertigo of vestibular origin (26 with acute peripheral vestibulopathy, five with Ménière's disease, three with benign paroxysmal positioning vertigo (BPPV), six with psychogenic vertigo) and the results compared with standard caloric reaction (CR). For CEMPs, clicks were delivered unilaterally via a pair of headphones. EMG activity was collected by surface electrodes placed on the sternocleidomastoid belly and averaged.

Results-In 29 patients, CR was unilaterally abnormal, pointing to a peripheral vestibular lesion. Seventeen of them had a corresponding loss of CEMPs; the other 12 patients had a normal CEMP. The remaining 11 patients had normal results in both tests. In comparison with $\mathrm{CR}$, CEMP showed a sensitivity of $59 \%$ and a specificity of $100 \%$ for peripheral vestibular disorders.

Conclusion-CR is a test of the horizontal canal whereas CEMP is thought to be a sacculus test. Different results of $C R$ and CEMP may be due to this difference between target organs stimulated and may be of prognostic value.
\end{abstract}

(F Neurol Neurosurg Psychiatry 1999;66:787-790)

Keywords: acute peripheral vestibulopathy; click evoked myogenic potentials; vestibulocollic reflex

In 1992, Colebatch et al described click evoked potentials that could be averaged out of the EMG activity of neck muscles ("click evoked myogenic potentials"; CEMPs). ${ }^{1}$ These responses were supposed to be evoked by vestibular afferents because patients with selective section of the vestibular nerve showed no potentials, whereas they could be recorded in patients with isolated sensorineural hearing loss. The authors called this phenomenon "vestibulocollic reflex" and suggested a saccular origin.

In the present study, we investigated the importance of these CEMPs in the differential diagnosis of patients presenting with acute vertigo of presumed vestibular origin as the leading complaint in comparison with caloric testing.

\section{Patients and methods}

PATIENTS

We examined 40 patients referred to the neurological or otorhinolaryngological clinic with acute vertigo as the leading complaint, and in whom, according to the clinical examination, a vestibular origin of vertigo was presumed. Twenty two were men (aged 29-76 years) and 18 were women (aged 19-72 years) with a mean age of 51 (SD 15) years. As a control group, 39 healthy subjects (19 women, 20 men; mean age 33 (SD 8) years; range 25-56 years) only underwent testing of CEMPs. All patients and healthy volunteers gave their informed consent.

\section{METHODS}

In each patient, recording of CEMP and caloric testing were performed. Three patients were repeatedly examined. Besides the neurological and ORL examination, additional radiological (cranial CT or MRI) and electrophysiological investigations (acoustic evoked potentials) were carried out, leading to the diagnoses listed in the table. In addition, 30 patients underwent pure tone audiometry. No patient had severe conductive hearing deficiency.

The vestibulocollic reflex was evoked by rarefaction clicks (duration $100 \mu \mathrm{s}$, loudness 110 $\mathrm{dB}$ NHL) delivered unilaterally to the ear by a pair of headphones. There was no adjustment to individual hearing loss. The stimulation rate was $5 \mathrm{~Hz}$. A continuous noise of $70 \mathrm{~dB}$ was presented to the contralateral ear. Recording of the EMG signal was achieved by surface electrodes which were mounted on sternocleidomastoid muscles symmetrically on both sides. The reference electrodes were placed on the clavicles. Patients were lying supine and had to lift their head during recording to reach tonic muscle contraction. ${ }^{1}$ Analysis time was $100 \mathrm{~ms}$ (sweep: 5-10 ms/division, sensitivity: $200 \mu \mathrm{V}$ /division). The signal was bandpass filtered from $20 \mathrm{~Hz}$ to $2 \mathrm{kHz}$. A total of 256 
recordings were averaged, and the responses were reproduced in a second turn. The time of the onset of the potential was often difficult to determine because its deflection from the baseline was not sharp, so we chose the latencies of the first positive (P1) and negative (N1) peaks; amplitudes were measured peak to peak (P1-N1). To give a relation of the amplitudes of both sides, we calculated their ratio (EP ratio $\left.^{2}\right)$ in the control group as: $\left(\left(\mathrm{Ampl}_{\text {big }}-\mathrm{Ampl}_{\text {small }}\right) /\left(\mathrm{Ampl}_{\text {big }}+\mathrm{Ampl}_{\text {small }}\right)\right) \times 100$ where $A_{m p l} b_{\text {big }}=$ bigger amplitude and $\mathrm{Ampl}_{\text {small }}=$ smaller amplitude and in the patient group as: $\left(\left(\mathrm{Ampl}_{\text {unaffected }}-\mathrm{Ampl}_{\text {affected }}\right) /\left(\mathrm{Ampl}_{\text {unaffected }}\right.\right.$ $\left.\left.+\operatorname{Ampl}_{\text {affected }}\right)\right) \times 100$.

Caloric stimulation was performed according to the established standard technique ${ }^{3}$ : The patient sat upright with the head reclined $60^{\circ}$. The ears were rinsed for 30 seconds with 100 $\mathrm{ml}$ water at $30^{\circ} \mathrm{C}$ and $44^{\circ} \mathrm{C}$. Nystagmus was registered by electronystagmography with the eyes shut. Vigilance was maintained by counting loud. The number of nystagmus beats was determined over a period of 30 seconds when nystagmus was maximal (culmination time $e^{4}$ ). A number of nystagmus beats below 35/30 s meant an impaired or reduced caloric reaction; below 15 beats $/ 30 \mathrm{~s}$, the thermal reaction was considered to be absent (normal range 35-68 beats/30 s).

\section{Results}

CONTROL GROUP

On the side of the click stimulation, a biphasic potential could be recorded: a positive peak (P1) with a mean latency of $11.6 \mathrm{~ms}$ (1.0) (all the values are presented as: mean (SD)) was followed by a negative peak (N1) with a mean latency of 20.0 (2.1) ms. The peak to peak amplitude was very variable (123 (68) $\mu \mathrm{V}$; range $26-382 \mu \mathrm{V})$. The right-left difference of P1 was $1.6 \mathrm{~ms}(1.4)$ and that of N1 was 0.9 (1.0) ms. The right-left difference of amplitudes was often considerable, up to a ratio of $4: 1$. The mean EP ratio was 23.5 (17.7; range $0.4-60.9)$.

\section{PATIENTS}

The results are shown in the table. Patients 1-26 had an acute peripheral vestibular lesion which was diagnosed by the characteristic clinical picture of abrupt onset of rotational vertigo, nausea, and vomiting, accompanied by spontaneous horizontal nystagmus. Twelve of them had unilateral loss of the caloric reaction on the affected side (figure), and in 11 of these patients, no CEMP could be elicited on the same side. The other case had no CEMPs on either side. Thirteen patients showed an impaired, but not absent CR. In nine of these, CEMPs were normal. Their mean EP ratio (18.4) and the side differences of the latencies

Patients and results of caloric testing and vestibulocollic reflex (VCR)

\begin{tabular}{|c|c|c|c|c|c|c|}
\hline Patient No & Age & Sex & Diagnosis & Time of test & $\begin{array}{l}\text { Caloric testing } \\
\text { Right/left }\end{array}$ & $\begin{array}{l}\text { CEMP } \\
\text { Right/left }\end{array}$ \\
\hline 1 & 56 & $M$ & Acute peripheral vestibulopathy on the right side & $\begin{array}{l}1 \\
10 \\
40 \\
107\end{array}$ & $\begin{array}{l}-/+ \\
-/+ \\
+/+\end{array}$ & $\begin{array}{l}-/+ \\
-/+ \\
+/+ \\
+/+\end{array}$ \\
\hline 2 & 38 & M & Acute peripheral vestibulopathy on the left side & 3 & $+1-$ & $+1-$ \\
\hline 3 & 73 & $\mathrm{M}$ & Acute peripheral vestibulopathy on the right side & 18 & $-1+$ & $-1+$ \\
\hline 4 & 46 & $\mathrm{~F}$ & Acute peripheral vestibulopathy on the right side & 4 & $-1+$ & $-1+$ \\
\hline 5 & 48 & $\mathrm{~F}$ & Acute peripheral vestibulopathy on the left side & 142 & $+1-$ & $+1-$ \\
\hline 6 & 57 & M & Acute peripheral vestibulopathy on the left side & $\begin{array}{l}9 \\
35\end{array}$ & $\begin{array}{l}+/- \\
+/+\end{array}$ & $\begin{array}{l}+/- \\
+/+\end{array}$ \\
\hline 7 & 61 & M & Acute peripheral vestibulopathy on the left side & 8 & $+1-$ & $+1-$ \\
\hline 8 & 44 & M & Acute peripheral vestibulopathy on the right side & 2 & $-1+$ & $-1+$ \\
\hline 9 & 55 & $\mathrm{~F}$ & Acute peripheral vestibulopathy on the right side & 7 & $-1+$ & $-1+$ \\
\hline 10 & 47 & M & Acute peripheral vestibulopathy on the left side & 6 & $+1-$ & $-1-$ \\
\hline 11 & 34 & $\mathrm{~F}$ & Acute peripheral vestibulopathy on the left side & 4 & $+/(-)$ & $+1+$ \\
\hline 12 & 72 & $\mathrm{~F}$ & Acute peripheral vestibulopathy on the left side & 11 & $+/(-)$ & $+1+$ \\
\hline 13 & 25 & $\mathrm{~F}$ & Acute peripheral vestibulopathy on the right side & 2 & $(-) /+$ & $+1+$ \\
\hline 14 & 37 & $\mathrm{M}$ & Acute peripheral vestibulopathy on the left side & 8 & $+/(-)$ & $+1+$ \\
\hline 15 & 68 & $\mathrm{M}$ & Acute peripheral vestibulopathy on the right side & 5 & $(-) /+$ & $+1+$ \\
\hline 16 & 19 & $\mathrm{~F}$ & Acute peripheral vestibulopathy on the left side & 2 & $+/(-)$ & $+1+$ \\
\hline 17 & 69 & $\mathrm{~F}$ & Acute peripheral vestibulopathy on the right side & 2 & $(-) /+$ & $+1+$ \\
\hline 18 & 29 & M & Acute peripheral vestibulopathy on the left side & 29 & $+/(-)$ & $+1+$ \\
\hline 19 & 33 & $\mathrm{~F}$ & Acute peripheral vestibulopathy on the right side & 42 & $(-) /+$ & $+1+$ \\
\hline 20 & 59 & M & Acute peripheral vestibulopathy on the left side & 17 & $+/(-)$ & $-1-$ \\
\hline 21 & 68 & M & Acute peripheral vestibulopathy on the left side & 6 & $+/(-)$ & $-1-$ \\
\hline 22 & 62 & M & Acute peripheral vestibulopathy on the left side & 10 & $+/(-)$ & $-1-$ \\
\hline 23 & 32 & $\mathrm{~F}$ & Acute hearing loss with vestibular affection on the right side & 30 & $-1+$ & $-1+$ \\
\hline 24 & 45 & $\mathrm{~F}$ & Acute hearing loss with vestibular affection on the left side & 4 & $+1+$ & $+1+$ \\
\hline 25 & 46 & $\mathrm{~F}$ & Hearing loss on both sides with vestibular affection after mumps & 4 years & $+/(-)$ & $-1-$ \\
\hline 26 & 52 & M & Traumatic labyrinth lesion on the right side & $\begin{array}{l}18 \\
9 \text { months }\end{array}$ & $\begin{array}{l}-1+ \\
-1+\end{array}$ & $\begin{array}{l}-1+ \\
-1+\end{array}$ \\
\hline 27 & 76 & M & Ménière's disease on the left side & Years, in interval & $+1-$ & $+1-$ \\
\hline 28 & 40 & $\mathrm{~F}$ & Ménière's disease on both sides & Years, in interval & $+1+$ & $+1+$ \\
\hline 29 & 50 & M & Ménière's disease on the right side & Years, in interval & $(-) /+$ & $+1+$ \\
\hline 30 & 40 & M & Ménière's disease on the left side & Years, in interval & $(-) /(-)$ & $+1+$ \\
\hline 31 & 72 & M & Ménière's disease on the right side & Years, in interval & $(-) /+$ & $+1+$ \\
\hline 32 & 73 & $M$ & BPPV & 1 & $+1+$ & $+1+$ \\
\hline 33 & 55 & $M$ & BPPV & 5 & $+1+$ & $+1+$ \\
\hline 34 & 61 & $\mathrm{~F}$ & $\mathrm{BPPV}$ & 7 & $+1+$ & $+1+$ \\
\hline 35 & 67 & $\mathrm{~F}$ & Psychogenic vertigo & 19 & $+/+$ & $+1+$ \\
\hline 36 & 56 & $\mathrm{~F}$ & Psychogenic vertigo & 7 & $+1+$ & $+1+$ \\
\hline 37 & 66 & $M$ & Psychogenic vertigo & 3 & $+1+$ & $+1+$ \\
\hline 38 & 23 & $\mathrm{~F}$ & Psychogenic vertigo & 6 months & $+1+$ & $+1+$ \\
\hline 39 & 50 & $\mathrm{~F}$ & Psychogenic vertigo & 6 months & $+1+$ & $+1+$ \\
\hline 40 & 57 & $M$ & Psychogenic vertigo & 4 & $+1+$ & $+/+$ \\
\hline
\end{tabular}

Time of the test=days between onset of symptoms and testing; +=normal; $-=$ absent; $(-)=$ impaired. 


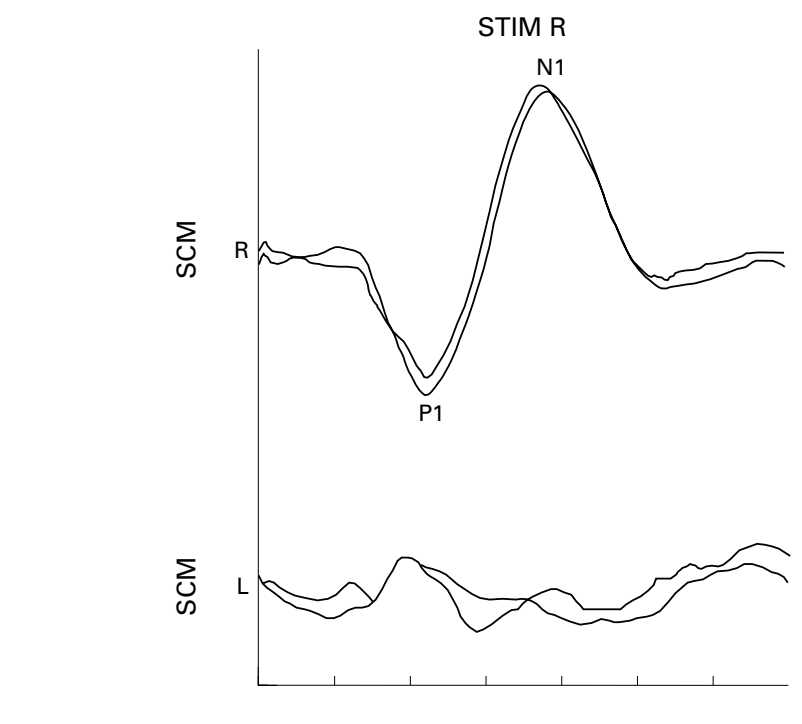

STIM R

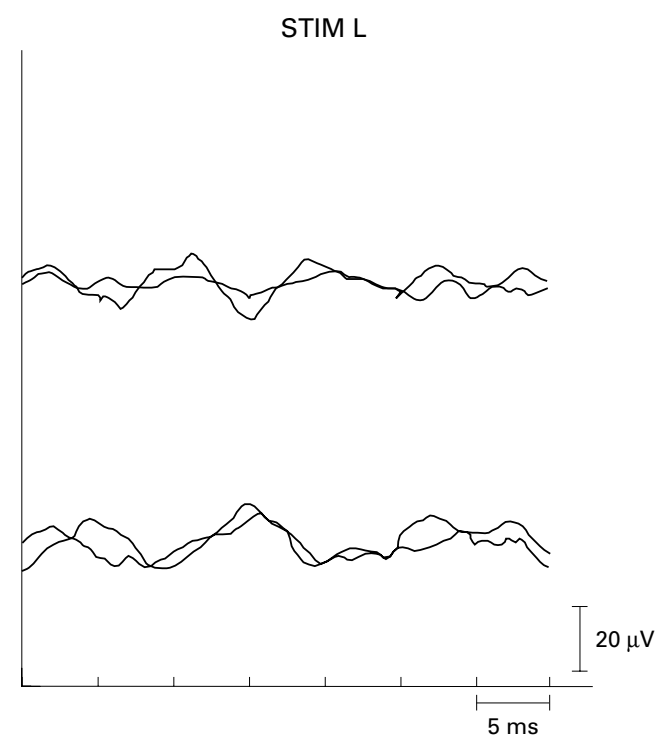

CEMPs in a patient with acute peripheral vestibulopathy on the left side, verified by caloric testing. On the right side (STIM R), a normal potential (P1N1) was elicited; on the left side (STIM L), the potential is absent. SCM=sternocleidomastoid muscle; STIM =stimulated ear.

of P1 ( $+0.05 \mathrm{~ms}$ on the affected side) and N1 $(+0.5 \mathrm{~ms}$ on the affected side) were not significantly different from the control group. In the other four cases, CEMPs were lacking on both sides. One patient (24) with an acute hearing loss had a normal caloric testing 4 days after the onset of symptoms with unequivocal clinical signs of vestibular affection. In this case, CEMP was normal, also.

Two patients with acute vestibulopathy were re-examined more than 5 weeks after the onset of vertigo, and both the caloric response and the CEMPs had reappeared. In the patient with traumatic loss of vestibular function, caloric response and click evoked vestibulocollic reflex had not returned more than 9 months after the accident.

Five patients had Ménière's disease. In one of them, CR was absent on the left side; CEMP could not be evoked on the same side. In three of these patients, CR was impaired on one or both sides. All of them had normal CEMPs. The last patient had normal CR and CEMP. In three patients with benign paroxysmal vertigo and in six patients with psychogenic vertigo, both caloric testing and CEMP were normal on both sides.

\section{Discussion}

Click evoked myogenic potentials of the neck muscles were first described by Bickford et al. ${ }^{6}$ They showed the dependence of the potential from a tonic muscle contraction. Colebatch et al demonstrated their origin by a "vestibulocollic reflex": In patients who had undergone selective section of the vestibular nerve the response was abolished, but it was preserved in patients with severe sensorineural hearing loss. Because of the short latency of the reflex, a rapidly conducting, disynaptic connection from the vestibular nuclei to the motor neurons of the neck muscles was presumed. A possible pathway may be the tractus vestibulospinalis medialis, located in the lateral medulla oblongata. ${ }^{8}$ Further papers disclosed a probable dependence on afferents arising from the saccule. ${ }^{2910}$ The exact generation of the potential is still unknown, but it seems to be caused by a synchronous change in motor unit activity. ${ }^{9}$

Our results in the control group correspond to previously reported value; CEMPs were always elicitable on the side of the click stimulation, and the latencies of P1 and $\mathrm{N} 1$ and the amplitudes were within the range of earlier reports. ${ }^{71}$ Halmagyi et al claimed a simultaneous measurement of mean rectified EMG during averaging in order to be able to express the amplitude relative to the level of tonic muscle contraction, which may differ between both sides. ${ }^{9}$ Thereby, they still found relations of up to $2.5: 1$ as normal.

In 40 patients with acute vertigo of presumed vestibular origin as the leading complaint, we found 13 cases with a unilateral absent response of caloric testing. In all of them, no CEMPs could be elicited on the corresponding side. This is by contrast with a series of 22 patients with unilateral loss of caloric response after vestibular neuritis, in which Halmagyi and Colebatch found an absent CEMP in only $11 . .^{12}$ In 16 patients, caloric testing gave an impaired, but not absent response on the affected side. In 12 of them, CEMP was normal. There were no significant side differences for latencies or amplitudes of the responses compared with the control group either. Murofushi et al also described patients with reduced thermal reaction but normal vestibulocollic reflex. ${ }^{2}$ This constellation may be due to the different target organs examinedthat is, the horizontal semicircular canal (caloric testing) and the saccule (CEMP). In the other four patients with impaired thermal reaction, CEMPs could not be evoked on either side, but they had no hearing problems in audiometry, which would have been more marked than in the other patients. Therefore, 
this result cannot be explained by conductive hearing deficiency. It has to be regarded as abnormal, because it was never found in the control group. Its meaning remains unclear. In the other 11 patients, both caloric testing and CEMPs were normal.

In conclusion, we found a good correlation of thermal reaction and CEMPs in patients with acute vertigo of presumed vestibular origin. In relation to the results of caloric testing, we found a sensitivity of CEMPs of around $59 \%$, and a specificity of $100 \%$. We could not find any significant side differences of amplitudes or latencies if CEMPs could be elicited on an affected side. A possible role of CEMPs in the prognostic evaluation of peripheral vestibulopathy still has to be examined. It may be presumed that a loss of CEMPs means a more severe lesion as the saccule is affected, too. A conductive hearing loss must always be ruled out in the evaluation of CEMP.

Pathological CEMPs can also be caused by central lesions in the vestibulocollic reflex pathway. Therefore, the constellation of a normal caloric testing and absent CEMP points to a brain stem lesion, which-according to the presumed pathway of the vestibulocollic reflex-will be located in the lateral medulla oblongata. Cases of medullar brain stem lesions (Wallenberg's syndrome) with a unilateral loss of CEMP have already been described. ${ }^{13}$ Thus, CEMPs may also be estab- lished as a complementary method for brain stem diagnostics.

1 Colebatch JG, Halmagyi GM. Vestibular evoked potentials in human neck muscles before and after unilateral vestibular deafferentiation. Neurology 1992;42:1635-6.

2 Murofushi T, Halmagyi GM, Yavor RA, et al. Absent vestibular evoked myogenic potentials in vestibular neurovestibular evoked myogenic potentials in vestibular neuro-
labyrinthitis. An indicator of inferior vestibular nerve involvement? Arch Otolaryngol Head Neck Surg 1996;122: involvem 845 .

3 Hallpike CS. The caloric test. Short description of its principles and practice. Acta Otorhinolaryngol Belg 1965;19: $360-6$

4 Claussen CF. Neurootologic methods for the differentiation of experimental ocular nystagmus. Berichte über die Zusammen-Küufte der Deutschen Ophthalmologischen Gesellschaft 1974;72:296-301.

5 Haid T. Positional tests in acute vestibular disorders. Adv Otorhinolaryngol 1981;27:176-89.

6 Bickford RG, Jacobson JL, Cody DTR. Nature of average evoked potentials to sound and other stimuli in man. Ann NY Acad Sci 1964;112:204-23.

7 Colebatch JG, Halmagyi GM, Skuse NF. Myogenic potentials generated by a click-evoked vestibulocollic potentials generated by a click-evoked vestibuloco
reflex. $\mathcal{F}$ Neurol Neurosurg Psychiatry 1994;57:190-7.

8 Nieuwenhuys R, Voogd J, Van Huijzen C. Das ZentralnervenNystem des Menschen. Berlin: Springer 1980.
sieuwentuys R,

system des Menschen. Berlin: Springer 1980. Halmagyi GM, Colebatch JG, Curthoys IS. New tests of
vestibular function. Baillieres Clin Neurol 1994;3:485-500.

10 Murofushi T, Curthoys IS, Topple AN, et al. Responses of guinea pig primary vestibular neurons to clicks. Exp Brain Res 1995;103:174-8.

$11 \mathrm{Lim}$ CL, Clouston P, Sheean G, et al. The influence of voluntary EMG activity and click intensity on the vestibular click evoked myogenic potential. Muscle Nerve 1995;18: 1210-3.

12 Halmagyi GM, Colebatch JG. Vestibular evoked myogenic potentials in the sternocleidomastoid muscle are not of lateral canal origin. Acta Otolaryngol (Stockh) 1995;(suppl 520): $1-3$.

13 Dillmann U, Heide G, Wollenberg I, et al. Der Klickevozierte vestibulo-kolläre Reflex bei topologisch definierten Hirnstammläsionen. Zeitschrift für Elektroencephalographie und Elektromyographie 1997;28:146-50. 